\title{
Profiles and Bioinformatics Analysis of Differentially Expressed Circrnas in Taxol- Resistant Non-Small Cell Lung Cancer Cells
}

\author{
Ning Xu Shaomu Chen ${ }^{\mathrm{c}}$ Yufeng Liu ${ }^{\mathrm{a}}$ Wei Lid Zeyi Liu \\ Xiaojie Bian ${ }^{\mathrm{d}}$ Chunhua Ling ${ }^{\mathrm{a}}$ Min Jiang $^{\mathrm{d}}$ \\ aDepartment of Respiratory Diseases, the First Affiliated Hospital of Soochow University, Suzhou, \\ bDepartment of Respiratory Diseases, the First People's Hospital of Lianyungang, Lianyungang, \\ 'Department of Thoracic Surgery, the First Affiliated Hospital of Soochow University, Suzhou, \\ 'Department of Oncology, the First Affiliated Hospital of Soochow University, Suzhou, China
}

\section{Key Words}

Circrna $\cdot$ NSCLC $\cdot$ Taxol resistance $\cdot$ Microarray $\bullet$ Bioinformatics analysis

\begin{abstract}
Background/Aims: Circular RNAs (circRNAs) act as microRNA (miRNA) sponges that regulate gene expression and are involved in physiological and pathological processes. In this study, we evaluated the roles of circRNAs in the chemoresistance of non-small cell lung cancer (NSCLC) to taxol. Methods: High-throughput circRNA microarrays were employed to investigate the circRNA profiles of parental A549 and taxol-resistant A549/Taxol cells. We predicted the miRNA targets of differentially expressed circRNAs via miRNA prediction software and then constructed a circRNA/miRNA network using Cytoscape. Bioinformatics analyses were performed to annotate dysregulated circRNAs in detail. Results: We detected 2909 significantly upregulated and 8372 downregulated circRNAs in A549/Taxol cells compared with A549 cells. The circRNA/miRNA network displayed their interactions, suggesting that circRNAs exert biological effects by absorbing and sequestering miRNA molecules. Computational Gene Ontology and pathway analyses were used to determine the biological function and signaling pathways of host genes of dysregulated circRNAs and to identify potential molecular mechanisms prompting the resistance of NSCLC to taxol. Conclusion: This study focusing on circRNAs related to taxol resistance provides a basis for clarifying the development and progression of drug resistance and for identifying therapeutic targets in NSCLC.
\end{abstract}




\section{Cellular Physiology Cell Physiol Biochem 2018;48:2046-2060

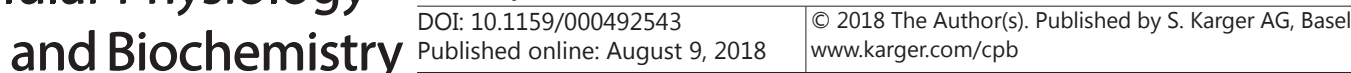

Xu et al.: Circrnas in Taxol-Resistant NSCLC

\section{Introduction}

Lung cancer, with a poor 5-year survival rate of approximately 15\% [1], is a major cause of cancer-related deaths worldwide [2]. Commonly, lung cancer is histologically classified into two main types with distinct clinical features, namely, non-small cell lung cancer (NSCLC), accounting for around 85\% of all cases [3], and small cell lung cancer (SCLC), with earlier brain metastasis [4]. Owing to the deficiency of sensitive biomarkers, numerous patients are diagnosed at an advanced stage, thereby limiting the opportunity for surgical resection. Paclitaxel, a microtubule-stabilizing agent targeting the taxane binding site and subsequently blocking depolymerization and inducing cell cycle arrest, belongs to a class of diterpenoid alkaloids with effective anti-tumor activity; it is widely used as the first-line chemotherapy regimen in the treatment of NSCLC [5]. At present, paclitaxel-based chemotherapy is a preferred choice for patients without the possibility of surgical intervention and has a critical role in lung cancer treatment [6-8]. However, the clinical efficacy of paclitaxel is often limited by ATP-binding cassette transporters, the overexpression of $\beta$-tubulin isoforms, alterations of mitotic checkpoints, and dysregulation of non-coding RNAs, leading to primary or secondary resistance to paclitaxel and eventually causing local recurrence and distant metastasis [6]. Thus, there is intense focus on chemotherapy resistance, one of the main challenges in the treatment of lung cancer. It is essential to search for the molecular processes by which patients with lung cancer develop resistance to chemotherapy regimens including paclitaxel.

Only less than $2 \%$ of human genomic sequences are protein-coding genes; the majority of the human transcriptome is non-coding RNA (ncRNA) with no ability to encode proteins [9]. It has been shown that microRNAs (miRNAs) and long non-coding RNAs (lncRNAs) could activate the initiation potential of diseases, particularly cancer, by regulating mRNA stability and translation via mRNA sequestration [10-12]. However, the peculiarities of circular RNAs (circRNAs), an enigmatic member of the RNA family, are not well characterized. CircRNAs were first observed nearly 40 years ago, but are recently recognized as regulatory molecules that are pervasive in the cytoplasm of eukaryocytes [13]. Initially, circRNAs were mistakenly interpreted as a fraction of splicing errors or functionless transcriptional byproducts during pre-mRNA splicing [14]. However, advances in high-throughput sequencing technologies and bioinformatics methods have shed light on their biogenesis, characteristics, and functions, demonstrating the dramatic diversity of RNAs and the complexity of eukaryotic transcriptomes $[15,16]$. Unlike linear RNAs with $5^{\prime}$ and $3^{\prime}$ termini, circRNAs possess a covalently closed loop structure generated from exon and/or intron circularization, which leads to the deletion of $5^{\prime}-3^{\prime}$ polarity and the polyadenylated tail [17]. In Eukarya, there is insufficient evidence to verify the capacity of circRNAs to encode proteins. Based on their origin from different regions of the genome, circRNAs could be loosely divided into three categories. Exonic circRNAs, representing the majority of circRNAs, are derived from direct back-splicing or exon skipping. Intronic circRNAs consist of lariat introns. Exonintron circRNAs contain both exons and introns $[16,18]$. Mounting evidence indicates that circRNAs could be free from RNase R digestion to protect the special circular construction and thus are more stable than linear mRNAs, possibly explaining their long half-lives $[19,20]$. Intriguingly, circRNAs are always highly abundant and exhibit evolutionary conservation and cell-, tissue-, or developmental stage-specific expression patterns across the eukaryotic tree of life [20-23]. These particular characteristics suggest prospective applications of circRNAs as diagnostic biomarkers. Extensive studies have examined the roles of circRNAs as miRNA sponges via miRNA response elements (MREs), alleviating the inhibitory effect of miRNAs on the stability and translation activity of target mRNAs [24]. The formation of circRNAs hiding translation start sites could impede the translation of residual linear transcripts, referred to as the "mRNA trap," indicating the competition of circRNAs with pre-mRNAs of their host genes [15, 25]. Additionally, circRNAs exert regulatory effects by binding to lncRNAs, transcription factors, and RNA-binding proteins, which, at the same time, results in feedback behavior on circRNA stability, abundance, and/or localization $[16,26]$. In aggregate, the mechanisms by which circRNAs modulate gene expression are intricate and 
variable. Moreover, the alteration of circRNA expression levels is common in response to stimuli, thereby influencing the biological behaviors of diseases [27]. There is a long way to go to characterize the landscape of circRNAs in biological processes.

In this study, we evaluated the expression profiles of circRNAs by a microarray analysis using the taxol-resistant cell line A549/Taxol and the sensitive A549 cell line. The interaction network and bioinformatics predictions based on the microarray results indicated that the resistance of NSCLC cells to taxol arise, in part, from the aberrant expression and complex function of circRNAs.

\section{Materials and Methods}

\section{Cell culture}

The human NSCLC cell line A549 and its taxol-resistant derivative A549/Taxol were obtained from Shanghai Institute of Materia Medica, Chinese Academy of Sciences (Shanghai, China). Resistant derivatives of A549 were selected by culturing in gradually increasing concentrations of paclitaxel from $10 \mathrm{nM}$ for a period of 6 months until a pool of cells was isolated that was able to grow at a concentration of $1 \mu \mathrm{M}$. A549 cells and A549/Taxol cells were cultured in Ham's F-12 medium and RPMI 1640 medium (Corning, Inc., Corning, NY, USA) supplemented with 10\% fetal bovine serum (Gibco, Grand Island, NY, USA). Cell culture flasks were placed in a humidified incubator with $5 \% \mathrm{CO}_{2}$ at $37^{\circ} \mathrm{C}$. The cells that reached $>80 \%$ confluency were passaged by trypsinization with trypsin/EDTA (Hyclone, Logan, UT, USA).

\section{Cell Counting Kit-8 assay}

The responsiveness of NSCLC cells to paclitaxel (Selleck, Houston, TX, USA) was evaluated by Cell Counting Kit-8 assays (CCK8; Dojindo, Kumamoto, Japan). Briefly, cells were seeded in 96-well plates at a density of 1500 A549 cells or 1000 A549/Taxol cells per well (in $100 \mu$ l of culture medium) and incubated overnight for attachment. The next day, A549 cells were subjected to treatment with paclitaxel at 0,2 , $10,50,250,500,1000$, or $2000 \mathrm{nM}$, and A549/Taxol cells were treated with $0,50,250,500,1000,2000$, 4000 , or $8000 \mathrm{nM}$. After $72 \mathrm{~h}, 10 \mu \mathrm{l}$ of CCK8 reagent was added to each well for $3 \mathrm{~h}$ of incubation at $37^{\circ} \mathrm{C}$. Subsequently, the absorption at $450 \mathrm{~nm}$ was recorded using an automatic microplate reader. Paclitaxel sensitivity was assessed by the $\mathrm{IC}_{50}$ value (defined as the drug concentration resulting in a $50 \%$ reduction of viability compared with the control) using SPSS statistics 17.0.

\section{RNA extraction and quality control}

Three samples were collected from each of the two cell lines. Total RNA was extracted using TRIzol reagent (Invitrogen, Carlsbad, CA, USA) and purified using the RNeasy MiniElute Cleanup Kit (QIAGEN, Hilden, Germany) according to the manufacturer's protocol. Prior to sample labeling, RNA quality and quantity were measured using the NanoDrop 1000 spectrophotometer (Thermo Fisher Scientific, Waltham, MA, USA). RNA integrity was evaluated by electrophoresis on a denaturing agarose gel.

\section{Microarray hybridization}

Sample preparation and microarray hybridization were completed according to the standard protocols of Agilent (Santa Clara, CA, USA). Isolated total RNA was subjected to RNase R (Epicentre, Madison, WI, USA) treatment to remove linear RNAs and enrich circRNAs. Then, enriched circRNAs were amplified and reverse transcribed into fluorescent cDNA using a random priming method. Next, the products were purified by Nucleospin $\circledast$ Extract II (Macherey-Nagel, Düren, Germany). The specific activity (pmol Cy3/ $\mu \mathrm{g} c \mathrm{DNA})$ and concentration $(\mu \mathrm{g} / \mu \mathrm{l})$ of the labeled cDNA were measured to assess the labeling efficiency using the NanoDrop 1000 spectrophotometer. The labeled cDNAs were hybridized onto the Agilent Human circRNA Array V1.0 $(4 \times 180 \mathrm{~K})$ to detect the profiles of 87,935 circRNAs. A mixture of $27.5 \mu \mathrm{l}$ labeled cDNA, $55 \mu \mathrm{l} 2 \times \mathrm{GEx}$ hybridization buffer, and $27.5 \mu \mathrm{l}$ formamide was heated at $95^{\circ} \mathrm{C}$ for $3 \mathrm{~min}$ and subsequently cooled for $2 \mathrm{~min}$ on ice. Finally, $105 \mu \mathrm{l}$ hybridization solution was dispensed into the gasket slide and the circRNA expression microarray slide was assembled. The hybridization device was incubated in an Agilent Hybridization Oven for $16 \mathrm{~h}$ at $65^{\circ} \mathrm{C}$. After hybridization, the slides were washed, fixed, and scanned 


\section{Cellular Physiology Cell Physiol Biochem 2018;48:2046-2060 \begin{tabular}{l|l} 
and Biochemistry Published online: August 9, 2018 & $\begin{array}{l}\text { (c) } 2018 \text { The Author(s). Published by S. Karger AG, Basel } \\
\text { www.karger.com/cpb }\end{array}$
\end{tabular}}

Xu et al.: Circrnas in Taxol-Resistant NSCLC

utilizing the Agilent Microarray Scanner G2565CA to obtain images. The original data for array images were exported by Agilent Feature Extraction V10.7. Microarray hybridization and data collection procedures were performed by CapitalBio Technology (Beijing, China).

\section{Microarray data analysis}

The quartile method was used to normalize the raw signal intensities and subsequent data processing steps were executed using the Agilent GeneSpring software package. The circRNAs with at least 3 out of 6 samples flagged as Present or Marginal were reserved as targets according to the instructions and definitions provided by GeneSpring for differential analysis. Based on a comparison of circRNA expression profiles between the two groups, the fold change (FC) for each circRNA was calculated. When FC $>2.0$ and $P \leq 0.05$, circRNAs were considered significantly differentially expressed. The significant differences in the expression of circRNAs between two groups were assessed using scatter plot filtering and volcano plot filtering. A hierarchical clustering analysis was used to obtain an overview of the differential circRNA expression profiles using Cluster and TreeView. Quantitative real-time PCR analyses were performed to confirm circRNA expression using SYBR Premix Ex Taq (Takara, Dalian, China), and GAPDH was utilized as an internal control. Pairs of PCR primers for eight selected circRNAs and GAPDH were as follows: 5'-CAAGCCGACTGATGACTGGAG-3' (forward) and 5'-AGTCGTCTTCGGCGTCAGA-3' (reverse) for hsa_circ_0080355, 5'-TTCCTCCAGTGCCTGTAACAC-3' (forward) and 5'-CAGGACCCACCACCACTACAT-3'

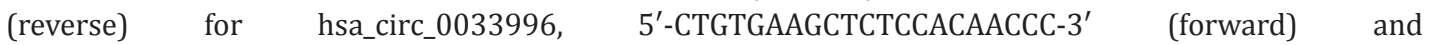
5'-CTGTGACCGGATCCTTCGTGT-3' (reverse) for hsa_circ_0001597, 5' - AGCCTCACCGCAAATCCCAG-3' (forward) and 5'-GCCAAGGAGAGAGAGGATGGA-3' (reverse) for hsa_circ_0003918, 5'-ACATCTACCAGGTCACTCCTGT-3' (forward) and 5'-ATGGTTCTTGGTCACACTGCCA-3' (reverse) for hsa_circ_0011292, 5' -CCTGTCCAAGGGTGGTGTCT-3' (forward) and 5'-GGCTCGGCTGTGCATCATAC-3' (reverse) for hsa_circ_0011298, 5' -GCCTCTTACAAGATGAGAAACTTGG-3' (forward) and 5'-GCAATTCCACGGGGTCTTCT-3' (reverse) for hsa_circ_0058608, 5' -TCACTCCTGTCTACCGCCTC-3' (forward) and 5'-AGTTGCCTTGGTCAAGAGGC-3' (reverse) for hsa_circ_0011293, and 5' -ACCCAGAAGACTGTGGATGG-3' (forward) and 5'-TCTAGACGGCAGGTCAGGTC-3' (reverse) for GAPDH.

\section{MiRNA prediction and circRNA/miRNA network}

MREs were detected in the differentially expressed circRNAs from microarray data and the target miRNAs were selected according to complementary seed sequences to establish the circRNA/miRNA network. Interactions were predicted using miRNA target prediction software, based on the previously built miRanda algorithm. The networks were constructed based on signal values of circRNAs and miRNAs normalized from the raw profiling data. The circRNA/miRNA interaction network was delineated using Cytoscape by annotating differentially expressed circRNAs and determining the correlations between circRNAs and corresponding miRNAs. Quantitative real-time PCR analyses were performed to confirm miRNA expression using SYBR Premix Ex Taq, and U6 was utilized as an internal control. Pairs of PCR primers for four selected miRNAs and U6 were as follows: $5^{\prime}$-CACATCCACCTCCTCCACATC-3' (forward) and 5'-AATGCGGCCGCAACTCAATCAACATCACCAT-3' (reverse) for miR-141, 5'-CGGAGGCAGTGTAGTTAGCT-3' (forward) and 5'-GTGCAGGGTCCGAGGT-3' (reverse) for miR-34c-5p, 5'-GGAAAGGCTCATTCGGACTA-3' (forward) and 5'-ACGACGCCACCAATCACT-3' (reverse) for miR-7, 5' -ACAGCAGGCACAGACAGG-3' (forward) and $5^{\prime}$-GTGCAGGGTCCGAGGT-3' (reverse) for miR-214, and 5'-TCAGTTTGCTGTTCTGGGTG-3' (forward) and $5^{\prime}$-CGGTTGGCTGGAAAGGAG-3' (reverse) for U6.

Gene Ontology and pathway analyses

Gene Ontology (GO) functional analysis and pathway analysis for circRNA host genes were performed to predict the functions of circRNAs using the Kyoto Encyclopedia of Genes and Genomes (KEGG) Orthology Based Annotation System (KOBAS), which covered one ontology database, seven pathway databases, and five human disease databases. The annotation of genes based on a wide range of taxa was implemented using a GO analysis, including analyses of the subgroups Biological Process (BP), Cellular Component (CC), and Molecular Function (MF). GO terms with $P<0.05$ were retained. A biological pathway analysis was performed using four databases (KEGG PATHWAY, Reactome, BioCyc, and Panther) defined by KOBAS to obtain pathway clusters, broadening our understanding of the molecular reaction networks and the 


\section{Cellular Physiology Cell Physiol Biochem 2018;48:2046-2060

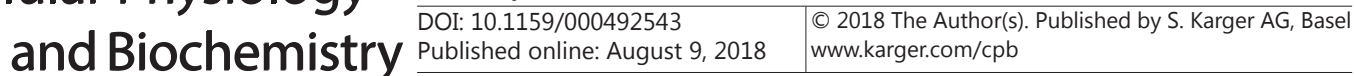 \\ Xu et al.: Circrnas in Taxol-Resistant NSCLC}

functional annotation of circRNA-related host genes. The GO and pathway terms for differentially expressed genes were ranked by enrichment score, defined as the $-\log (P$-value $)$ for the significance of GO term enrichment scores and pathway correlations.

\section{Statistical analysis}

All quantitative data from at least three independent experiments are presented as the mean \pm standard deviation. The statistical significance of circRNA differences between samples was determined using Student's $t$-tests. $P \leq 0.05$ indicated statistical significance.

\section{Results}

Morphological features and validation of taxol resistance in the A549/Taxol cell line

The taxol-resistant NSCLC cell line was developed from the parental A549 cell line via taxol induction. The resulting pool, termed A549/Taxol for "paclitaxel resistance," exhibited the epithelial-mesenchymal transition (EMT) phenotype [28-30]. Our observations of morphological changes in A549/Taxol cells were consistent with those of previous reports. As visualized by optical microscopy, A549/Taxol cells appeared to be spindle-shaped and elongated, while A549 cells exhibited a round shape (Fig. 1A). The leaky intercellular adhesion and increased formation of pseudopodia in the A549/Taxol cell line may strengthen the nature of cell migration and invasion. CCK8 assays were adopted to evaluate the viability of A549/Taxol and A549 cells after taxol exposure. We found that the $\mathrm{IC}_{50}$ values of taxol for A549 cells and A549/Taxol cells were 17.22 $\pm 1.71 \mathrm{nM}$ and $1265.63 \pm 139.96 \mathrm{nM}$, respectively $\left(P<0.05\right.$, Fig. 1B). The $\mathrm{IC}_{50}$ of taxol differed substantially between the two cell lines by 72.87 times, suggesting that the A549/Taxol cell line was indeed more resistant than the parental A549 cell line.

Overview of differential circRNA expression profiles

We detected approximately 88000 circRNAs in three pairs of samples by a highthroughput microarray assay. The differentially expressed circRNAs between groups are displayed in scatter plots in Fig. 2A. Additionally, volcano plots show statistically significant differences in circRNA expression (Fig. 2B). An expression profile analysis of these circRNA transcripts indicated that 11281 circRNAs are differentially expressed between the A549/ Taxol and A549 cell lines (FC $>2.0$ and $P \leq 0.05$ ). Among these, 2909 circRNAs were upregulated and 8372 were downregulated. The number of upregulated circRNAs was almost 3 times lower than the number of downregulated circRNAs (Fig. 2C). A hierarchical clustering analysis also indicated that circRNA expression patterns in A549/Taxol cells differed from

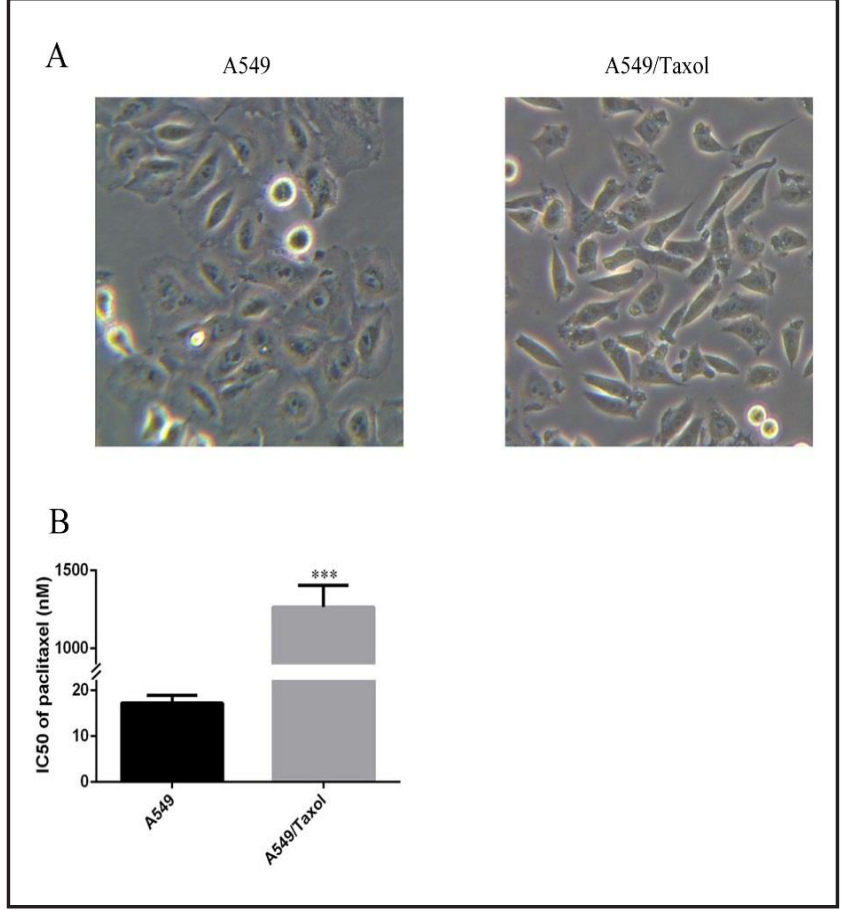

Fig. 1. Morphology of cells and the response to taxol treatment in two cell lines. (A) A549/Taxol cells exhibit an EMT-like appearance distinguishable from A549 cells. (B) The $\mathrm{IC}_{50}$ values of taxol in A549/Taxol cells were significantly higher than those of A549 cells ( $\left.{ }^{* *} \mathrm{P}<0.001\right)$. 
Fig. 2. Differences and features of circRNA expression patterns in two cell lines. (A) Scatter plots provide a visual overview of the differentially expressed circRNAs between the two groups. Red and green points represent more than 2.0-fold upregulated and downregulated circRNAs, respectively. Black points indicate circRNAs without differential expression. (B) Volcano plots show the statistically significant differences in circRNA expression based on FC and P-values for microarray data. The vertical lines are consistent with 2.0-fold upregulation and downregulation between resistant and parental groups. The horizontal line corresponds to a P-value of 0.05 . Red and green points in the plots mark significantly upregulated and downregulated circRNAs by more than 2.0-fold, respectively. (C) More circRNAs are apparently downregulated than upregulated. (D) Hierarchical clustering analysis shows different expression profiles of all target circRNAs. Each column corresponds to a sample and each row corresponds to a circRNA. Red strips indicate upregulation and green strips indicate downregulation. (E) Hierarchical cluster analysis shows the top 20 upregulated and downregulated circRNAs. (F) Genomic distribution of differently expressed circRNAs.

(G) Validation of selected circRNA expression levels by real-time PCR.

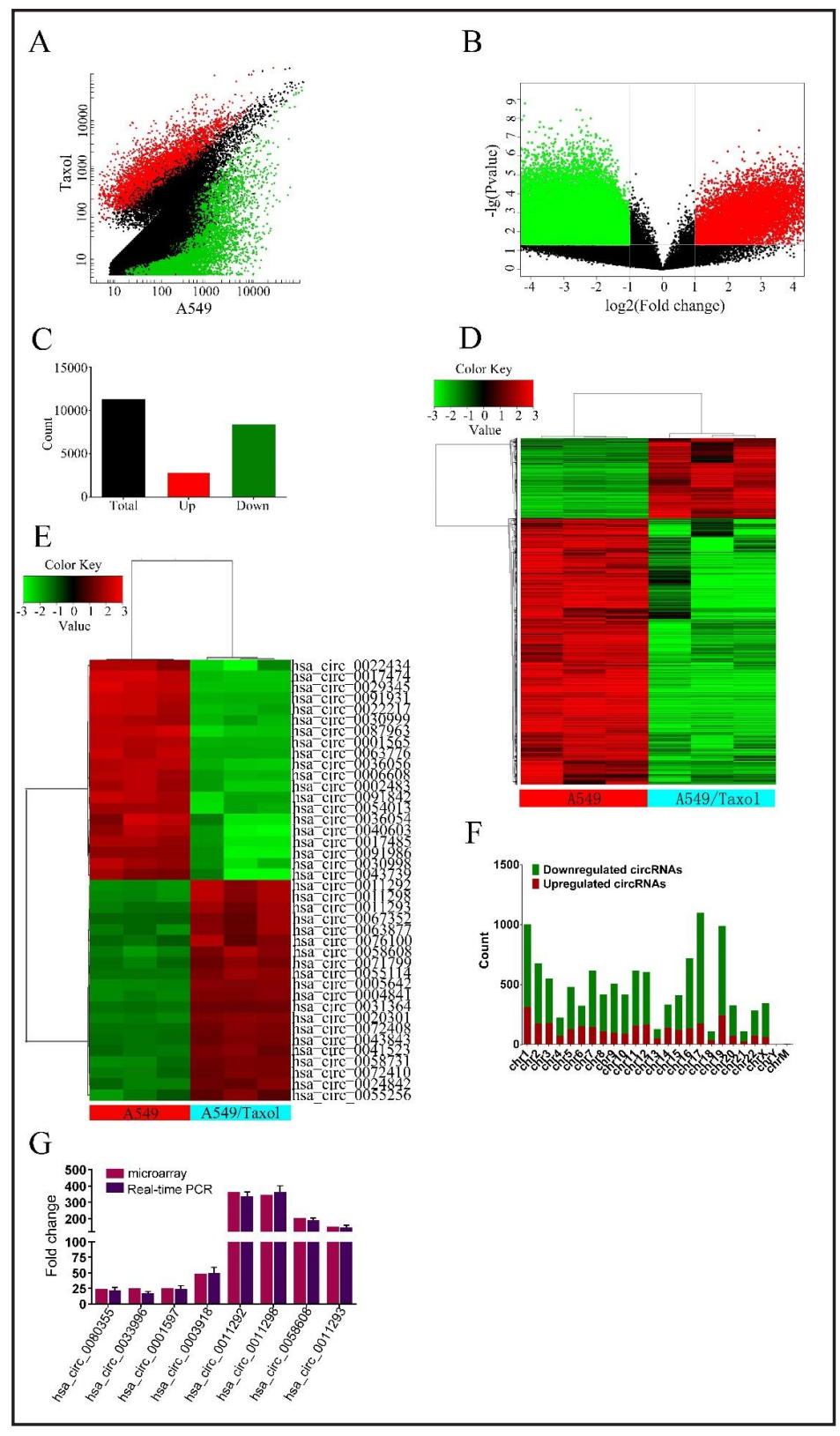

those in A549 cells (Fig. 2D). The top 20 upregulated and downregulated circRNAs ranked by fold change are listed in a clustered heat map (Fig. 2E) and in Table 1. These circRNAs were located in a variety of genomic locations, including sex chromosomes. A subgroup analysis of the genomic distribution showed that chr17 is the primary region for host genes of differentially expressed circRNAs, representing $9.73 \%$ of host genes, followed by $8.87 \%$ for chr1 and $8.75 \%$ for chr19 (Fig. 2F). These data suggest that dysregulated circRNA expression is associated with the resistance of NSCLC to taxol. We focused on the roles of upregulated circRNAs in taxol-resistant NSCLC and chose candidate circRNAs for further experiments according to miRNAs as well as FC. We searched the literature for miRNAs involved in the resistance of cancers to taxol and ranked the upregulated circRNAs based on a quantitative estimate of taxol resistance-related miRNAs that bound to each circRNA (Table 2). 
Table 1. Top 20 upregulated and downregulated circRNAs by FC

\begin{tabular}{|c|c|c|c|c|c|}
\hline CircRNA & Regulation & FC & $P$ & Gene symbol & No. miRNA \\
\hline hsa_circ_0011292 & up & 363.0308 & $4.81 \mathrm{E}-05$ & TINAGL1 & 14 \\
\hline hsa_circ_0011298 & up & 346.7428 & $7.00 \mathrm{E}-05$ & TINAGL1 & 1 \\
\hline hsa_circ_0058608 & up & 202.7038 & $8.58 \mathrm{E}-05$ & SP140L & 4 \\
\hline hsa_circ_0005642 & up & 175.984 & $3.93 \mathrm{E}-07$ & JMJD5 & 114 \\
\hline hsa_circ_0004841 & up & 156.771 & $5.53 \mathrm{E}-07$ & JMJD5 & 114 \\
\hline hsa_circ_0011293 & up & 152.1076 & $9.41 \mathrm{E}-05$ & TINAGL1 & 8 \\
\hline hsa_circ_0020301 & up & 152.0181 & $1.38 \mathrm{E}-06$ & CPXM2 & 1 \\
\hline hsa_circ_0063877 & up & 136.0419 & 0.000268 & PIM3 & 81 \\
\hline hsa_circ_0055114 & up & 133.3505 & $2.54 \mathrm{E}-05$ & TIA1 & 15 \\
\hline hsa_circ_0058731 & up & 106.8064 & $1.47 \mathrm{E}-05$ & GIGYF2 & 34 \\
\hline hsa_circ_0071799 & up & 97.67049 & $5.85 \mathrm{E}-05$ & SEMA5A & 93 \\
\hline hsa_circ_0076100 & up & 95.67535 & 0.000822 & ZNF76 & 0 \\
\hline hsa_circ_0072408 & up & 95.55496 & $3.10 \mathrm{E}-06$ & NNT & 9 \\
\hline hsa_circ_0072410 & up & 90.78973 & $2.02 \mathrm{E}-05$ & NNT & 41 \\
\hline hsa_circ__0 041523 & up & 90.12102 & $1.56 \mathrm{E}-05$ & CYBSD2 & 13 \\
\hline hsa_circ_0024842 & up & 87.8954 & $5.23 \mathrm{E}-05$ & ARHGAP32 & 1 \\
\hline hsa_circ_0067352 & up & 81.43763 & 0.00019 & CPNE4 & 1 \\
\hline hsa_circ__0043843 & up & 80.95976 & $3.03 \mathrm{E}-06$ & NAGWU & 74 \\
\hline hsa_circ_0031364 & up & 78.6552 & $8.43 \mathrm{E}-08$ & TINF2 & 53 \\
\hline hsa_circ_0055256 & up & 76.79103 & 0.000684 & ACTG2 & 36 \\
\hline hsa_circ_0087963 & down & 2152.979 & $2.88 \mathrm{E}-06$ & LPAR1 & 0 \\
\hline hsa_circ_0029345 & down & 2140.493 & $1.91 \mathrm{E}-06$ & SCARB1 & 2 \\
\hline hsa_circ_0017474 & down & 2119.118 & $2.06 \mathrm{E}-06$ & PFKP & 31 \\
\hline hsa_circ_0040603 & down & 1556.446 & 0.000401 & CMIP & 0 \\
\hline hsa_circ_0036056 & down & 1406.517 & $2.31 \mathrm{E}-06$ & CLN6 & 0 \\
\hline hsa_circ_0036054 & down & 1233.177 & 0.00109 & CLN6 & 8 \\
\hline hsa_circ_0091931 & down & 1223.785 & $1.55 \mathrm{E}-06$ & FLNA & 353 \\
\hline hsa_circ_0022217 & down & 1183.605 & $1.21 \mathrm{E}-05$ & PRPF9 & 48 \\
\hline hsa_circ_0022434 & down & 1157.387 & 0.000718 & EEFIG & 13 \\
\hline hsa_circ_0091842 & down & 1157.369 & $5.64 \mathrm{E}-05$ & FLNA & 258 \\
\hline hsa_circ_0017485 & down & 1151.725 & 0.000232 & PFKP & 7 \\
\hline hsa_circ__0063776 & down & 1032.733 & $4.45 \mathrm{E}-06$ & MIRLET7BHG & 2 \\
\hline hsa_circ__0001565 & down & 964.5138 & $1.22 \mathrm{E}-08$ & CANX & 1 \\
\hline hsa_circ__0043739 & down & 940.9911 & 0.002208 & ACLY & 18 \\
\hline hsa_circ_0002483 & down & 901.392 & $4.14 \mathrm{E}-05$ & РTK2 & 0 \\
\hline hsa_circ_0030998 & down & 859.863 & 0.000196 & LAMP1 & 1 \\
\hline hsa_circ_0006608 & down & 839.0563 & $8.57 \mathrm{E}-06$ & PFKP & 1 \\
\hline hsa_circ_0091986 & down & 832.9666 & 0.000473 & FLNA & 191 \\
\hline hsa_circ_0054013 & down & 829.7856 & $5.77 \mathrm{E}-05$ & CRIM1 & 46 \\
\hline hsa_circ_0030999 & down & 746.9171 & $7.72 \mathrm{E}-06$ & LAMP1 & 22 \\
\hline
\end{tabular}

\section{Prediction and establishment} of the circRNA-miRNA interaction network

CircRNAs act as miRNA sponges to manipulate gene expression. Since the functions of circRNAs remain poorly understood, we theoretically predicted target miRNAs of all differentially expressed circRNAs based on conserved miRNA matching sequences using miRNA target prediction software and the miRanda database. According to the microarray data, we then established a partial circRNA/miRNA interaction network using Cytoscape, delineating interactions of the most highly upregulated and downregulated circRNAs with complementary miRNAs (Fig. 3). The lines connecting circRNAs with miRNAs display close correlations and regulatory interactions. The annotations of all circRNAs in the circRNA/ miRNA network were not fully unveiled, but several circRNA-associated miRNAs are involved in taxol-resistant cancers. The overexpression of miR-141 increases the response of resistant
A

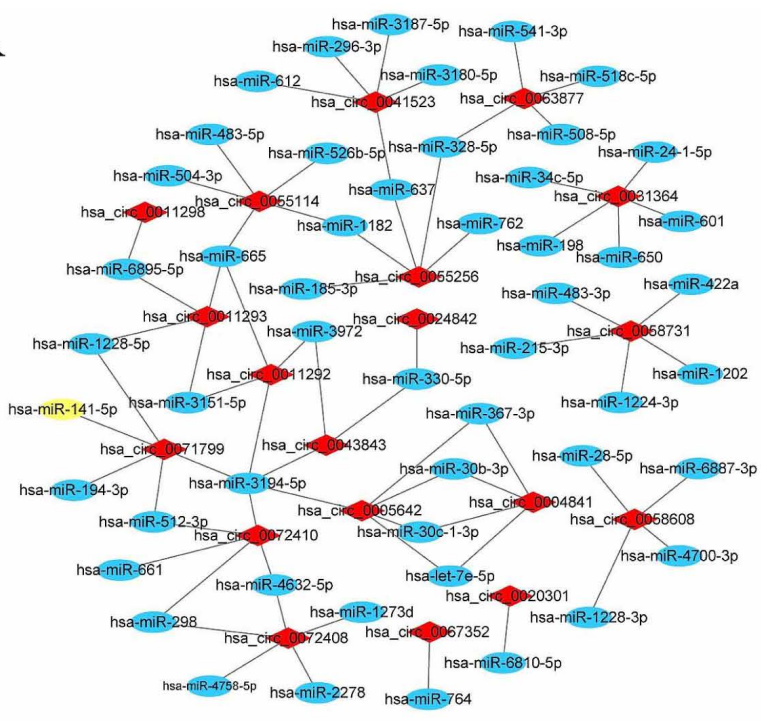

B

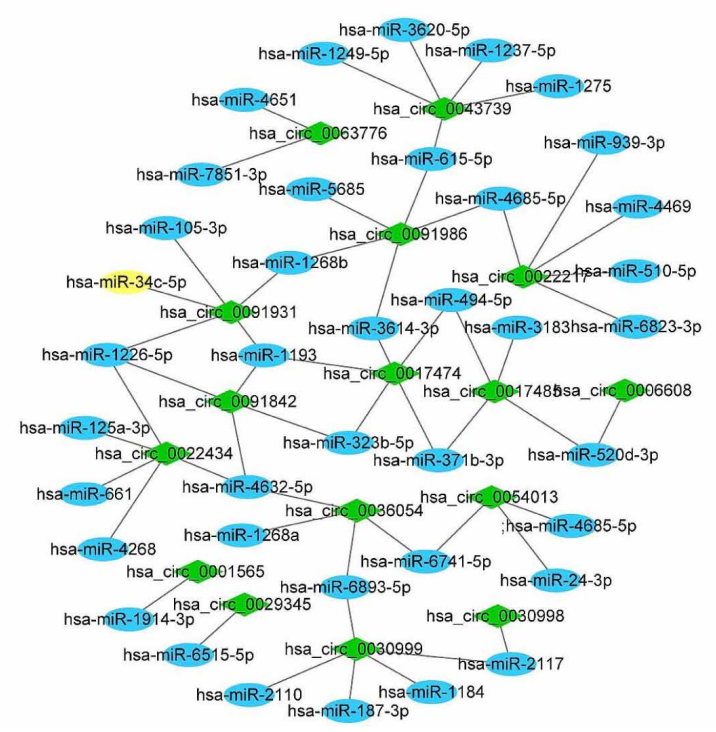

Fig. 3. circRNA/miRNA network. (A) The network depicts the most highly upregulated circRNAs and their target miRNAs. Red diamonds represent upregulated circRNAs. Blue and yellow ellipses represent miRNAs. (B) The network depicts the highly most downregulated circRNAs and their target miRNAs. Green diamonds represent downregulated circRNAs. Blue and yellow ellipses represent miRNAs. 


\section{Cellular Physiology Cell Physiol Biochem 2018;48:2046-2060 \begin{tabular}{l|l} 
DOI: 10.1159/000492543 & and Biochemistry \\
Published online: August 9, 2018 & $\begin{array}{l}\text { O 2018 The Author(s). Published by S. Karger AG, Basel } \\
\text { www.karger.com/cpb }\end{array}$
\end{tabular} \\ Xu et al.: Circrnas in Taxol-Resistant NSCLC}

ovarian cancer cells to taxol treatment, while the knockdown of miR-141 in sensitive cells drives resistance to taxol [31]. MiR-34c-5p conferred the notable resistance of lung cancer to taxol-mediated apoptosis via p53 downregulation, silencing its target genes Bcl-2-modifying factor (Bmf) and c-myc [32]. Among the top 20 differentially expressed circRNAs, one upregulated circRNA, hsa circ_0071799, is related to miR-141 (Fig. 3A and 4A), and one downregulated circRNA, hsa_circ_0091931, interacts with miR-34c-5p (Fig. 3B and 4B). Collaboratively, these results suggest that circRNAs enhance the resistance to taxol in NSCLC depending on a negative relation with the expression levels of miRNA transcripts.
Fig. 4. Detailed binding of circRNAs to miRNAs. (A) hsa circ_0071799. hsa_circ_0091931. (C) Validation of expression levels of miR-141, miR-34c$5 \mathrm{p}, \mathrm{miR}-7$, or miR214 by real-time PCR in taxol-resistant cells compared with sensitive cells.

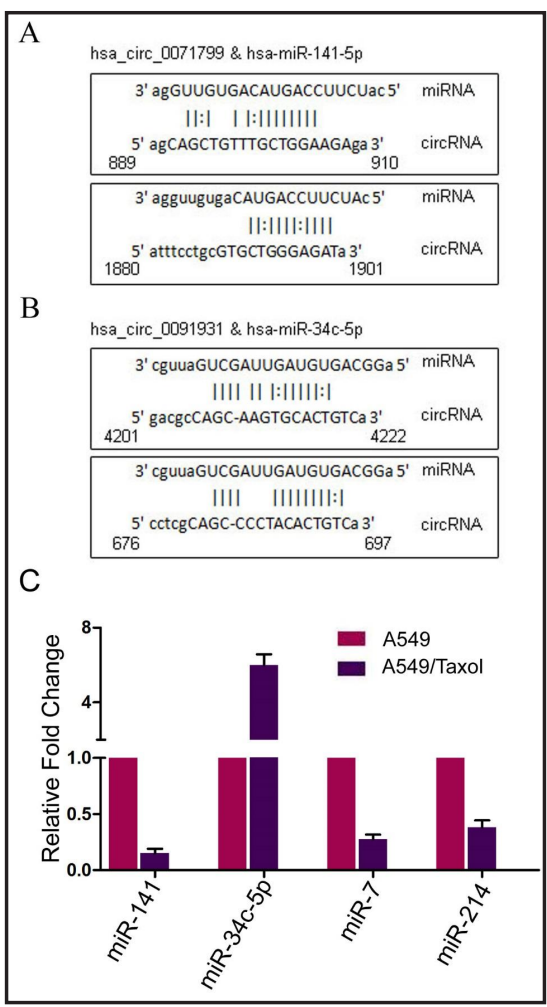

Table 2. Top 20 upregulated circRNAs by the number of taxol resistance-related miRNAs

\begin{tabular}{lc}
\hline CircRNA & No. miRNA \\
\hline hsa_circ_0068512 & 37 \\
hsa_circ_0043602 & 36 \\
hsa_circ_0033738 & 35 \\
hsa_circ_0033898 & 35 \\
hsa_circ_0036948 & 35 \\
hsa_circ_0069858 & 35 \\
hsa_circ_0076872 & 35 \\
hsa_circ_0080355 & 35 \\
hsa_circ_0080978 & 35 \\
hsa_circ_0000693 & 34 \\
hsa_circ_0033995 & 34 \\
hsa_circ_0033996 & 34 \\
hsa_circ_0033689 & 34 \\
hsa_circ_0001597 & 33 \\
hsa_circ_0033735 & 33 \\
hsa_circ_0033737 & 33 \\
hsa_circ_0033743 & 33 \\
hsa_circ_0033750 & 33 \\
hsa_circ_0033768 & 33 \\
hsa_circ_0033879 & 33 \\
& \\
\hline
\end{tabular}


Fig. 5. GO analysis of host genes of differentially expressed circRNAs. (A) Significantly enriched GO terms by enrichment score were analyzed for the host genes of upregulated circRNAs. (B) Significantly enriched GO terms by enrichment score were analyzed for the host genes of downregulated circRNAs.

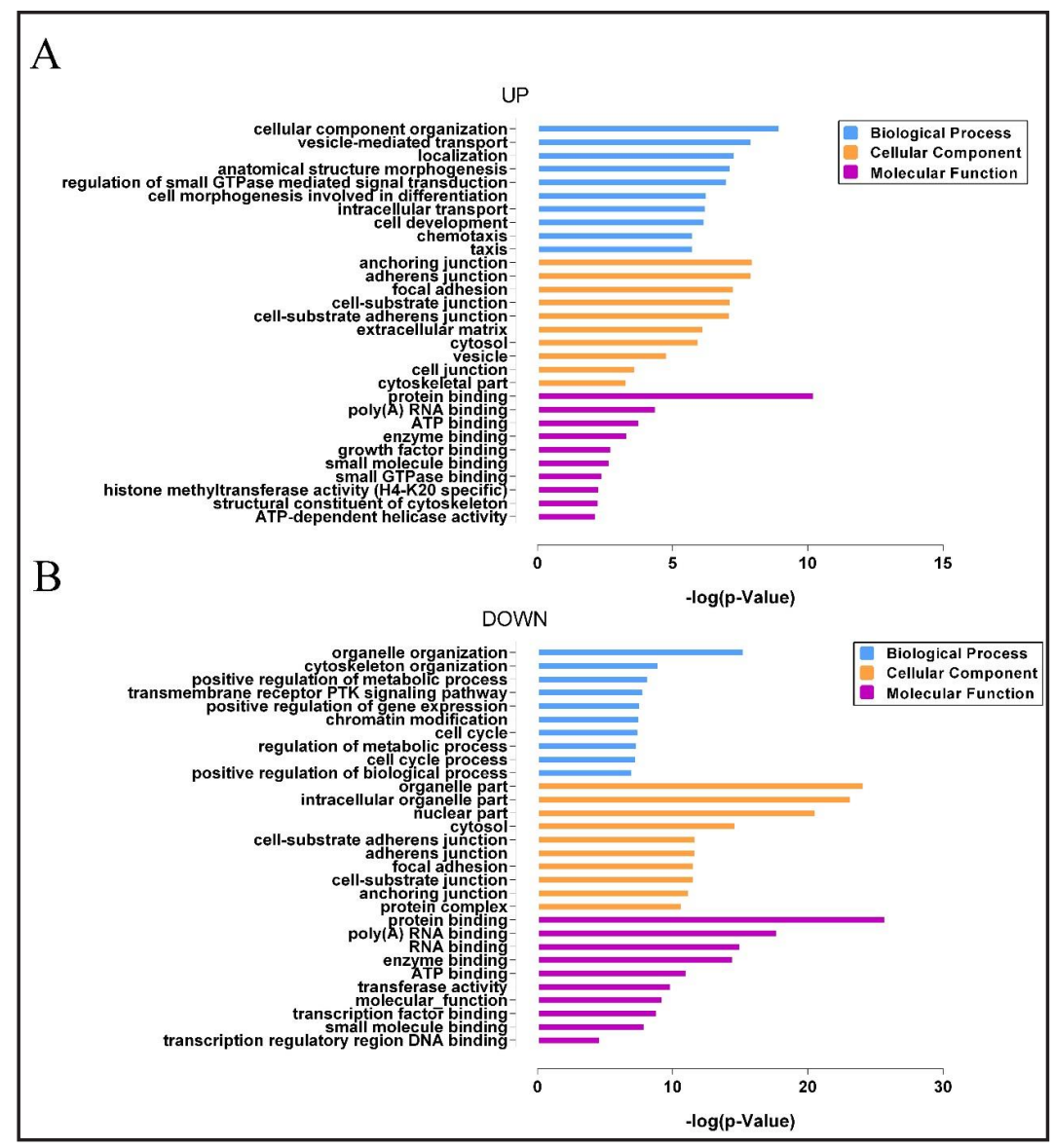

Fig. 6. Prediction of host gene-mediated signaling pathways. (A) Significantly enriched pathway terms by enrichment score were analyzed for the host genes of upregulated circRNAs. (B) Significantly enriched pathway terms by enrichment score were analyzed for the host genes of downregulated circRNAs.

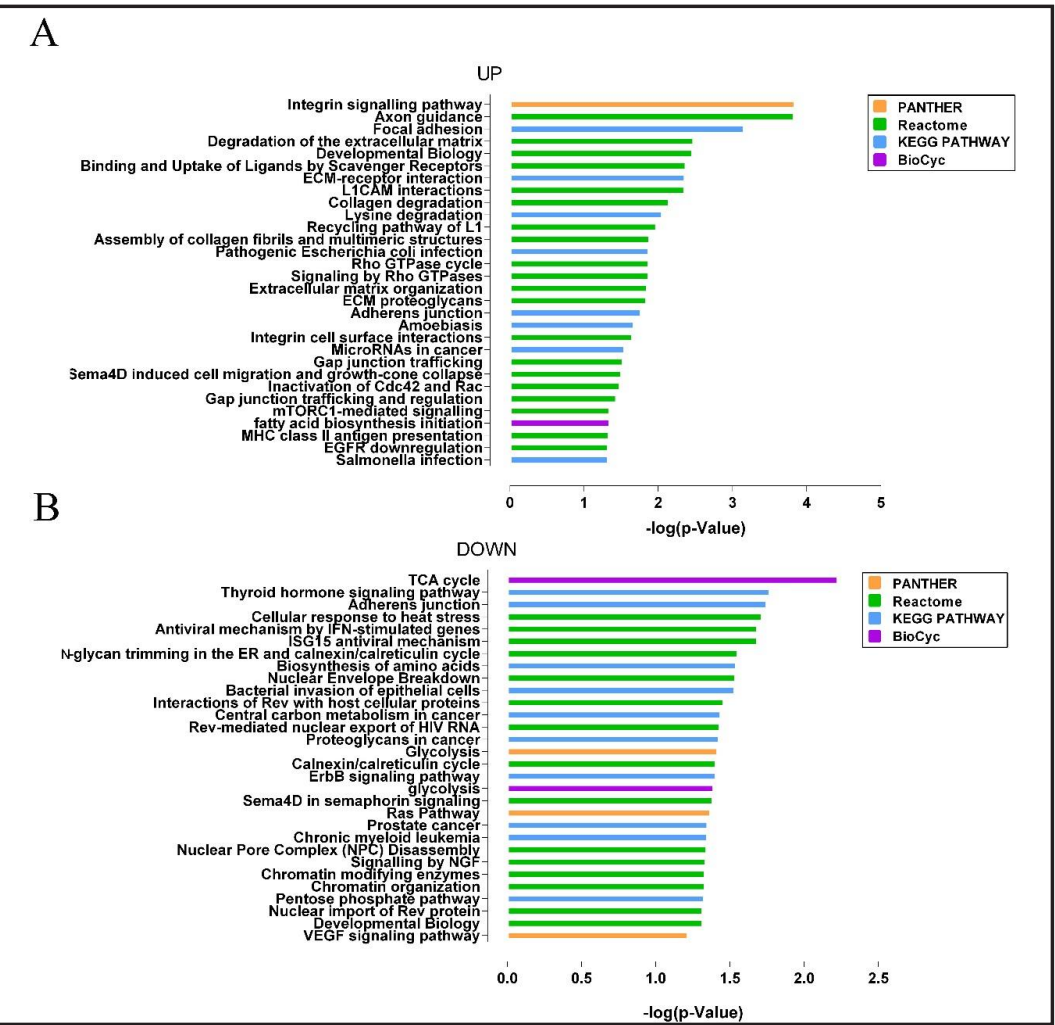




\section{Cellular Physiology Cell Physiol Biochem 2018;48:2046-2060 \\ and Biochemistry Published online: August 9, $2018 \quad \begin{aligned} & \text { DOI: 10.1159/000492543 } 2018 \text { The Author(s). Published by S. Karger AG, Basel } \\ & \text { www.karger.com/cpb }\end{aligned}$ \\ Xu et al.: Circrnas in Taxol-Resistant NSCLC}

most significantly enriched MF terms included protein binding, enzyme binding, transferase activity, and transcription factor binding. Among these GO terms, the metabolic process, cell cycle, focal adhesion, and transferase activity were crucial in regulating cell proliferation, migration, and gene expression and, as a result, are implicated in human tumorigenesis and metastasis. The resistance to taxol in NSCLC cells could be attributed to the aforementioned biological processes and molecular functions.

We used four databases defined by KOBAS to determine pathways and molecular interactions associated with parent genes. The most significantly enriched pathways for aberrant circRNA-related host genes are summarized in Fig. 6. For host genes of upregulated circRNAs, the most highly enriched pathways included the integrin signaling pathway, focal adhesion, degradation of the extracellular matrix, signaling by Rho GTPases, integrin cell surface interactions, and EGFR downregulation. For host genes of downregulated circRNAs, the most highly enriched pathways included the adherens junction, ErbB signaling pathway, and VEGF signaling pathway. These signaling pathways are involved in the progression of the resistance of cancers to chemotherapeutic drugs, including paclitaxel [35-43].

\section{Discussion}

Chemotherapeutic agents are limited by acquired resistance, which has undoubtedly become a stumbling block to the successful treatment and management of lung cancer [29]. To date, methods to resist drug resistance and improve clinical outcomes have not been developed, despite extensive studies. A number of pathological and molecular mechanisms related to chemoresistance have been evaluated. miRNAs and lncRNAs are often involved in controlling these complex processes in lung cancer [29, 30, 44-46]. Recent research has focused on the contribution of circRNAs to gene regulation. Hundreds of circRNAs are more highly expressed and more easily detected than homologous linear mRNAs in human saliva and peripheral blood [47, 48], suggesting that circRNAs are satisfactory biomarkers for non-invasive examinations. CircRNAs are also of paramount importance in many kinds of diseases and tumorigenesis. For instance, ciRS-7 depletion indirectly leads to a reduction of the ubiquitin conjugating enzyme UBE2A via excessive miRNA-7 in Alzheimer's disease [49]. The upregulation of hsa_circ_001569 and hsa_circ_0000069 augments cell proliferation, migration, and invasion, and hsa_circ_001988 downregulation is used as an indicator in colorectal cancer [50-52]. CircPVT1 was believed to be a proliferative effector and a prognostic factor based on an analysis of RNA-sequencing data in gastric cancer [53]. In addition, hsa_circ_002059 might be a new biomarker for gastric carcinoma [54]. CircRNAs are also abnormally expressed in esophageal cancer [55], cutaneous squamous cell carcinoma [56], and hepatocellular carcinoma [57].

However, the functions of deregulated circRNAs in taxol-resistant NSCLC are still elusive. We comprehensively analyzed genome-wide differential circRNA expression in the parental A549 cell line and resistant A549/Taxol cell line using a circRNA microarray. The aberrant differential expression of 11281 circRNAs was detected in a comparison of the A549/Taxol group and matched controls, including 2909 upregulated and 8372 downregulated circRNAs. The upregulated circRNAs hsa_circ_0011292, hsa_circ_0011298, and hsa_circ_0011293 are spliced from TINAGL1, which is upregulated in highly metastatic cancers and might be an excellent target gene for hampering the metastasis of NSCLC [58]. JMJD5, which splices hsa_circ_0005642 and hsa_circ_0004841, is localized in both the nucleus and cytoplasm and modulates microtubule stability by affecting the acetylation and detyrosination of $\alpha$-tubulin via the regulation of MAP1B levels, and its depletion markedly increases the sensitivity of cancer cells to microtubule-destabilizing agents [59]. The inactivation of PIM3, which splices hsa_circ_0063877, decreases the chemoresistance of docetaxel by apoptosis and clonogenicity inhibition by reducing the expression of LC3II and Beclin-1 [60]. With respect to the most highly downregulated circRNAs, LPAR1 splices hsa_circ_0087963 and its inhibitor, a drug candidate, prevents the formation of 


\section{Cellular Physiology Cell Physiol Biochem 2018;48:2046-2060

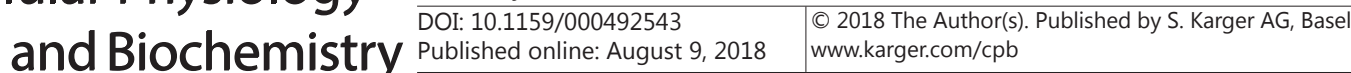 \\ Xu et al.: Circrnas in Taxol-Resistant NSCLC}

metastatic niches in breast cancer [61]. Hsa_circ_0029345 is spliced from SCARB1, which is an independent prognostic factor related to tumor aggressive behavior in breast cancer [62]. FLNA splices hsa_circ_0091931 and mediates the angiogenesis pathway involved in the deterioration of lung cancer [63]. Hence, most host genes were involved in the progression or drug resistance of human cancers. We speculated that abnormal circRNAs with greater fold changes were more likely to explain the resistance of NSCLC to taxol.

circRNAs with MREs could be candidate competing endogenous RNAs (ceRNAs), which compete for miRNA binding against other endogenous RNA transcripts via conserved seed sequence pairing [24,33]. The members of ceRNAs include mRNAs, IncRNAs, circRNAs, and pseudogene transcripts in addition to circRNA accessions [64]. Under normal circumstances, these transcripts could maintain a dynamic balance in the cellular context by competitively binding to miRNAs. CircRNAs could serve as miRNA sponges and negatively regulate the activity of miRNAs. As the most thoroughly studied and best characterized circRNA, the circRNA CiRS-7 (Cdr1as) contains more than 70 binding sites for miRNAs. It has been corroborated that miR-7 could reduce the expression levels of oncogenes related to cancerrelated signaling circuits, including EGFR, Raf1, IGF1R, and $m T O R$, subsequently blocking EMT, anchorage-independent growth, and metastasis. Therefore, the overexpression of ciRS7 enhances targeted mRNAs by the negative regulation of the tumor suppressor miR-7 [6567]. In esophageal squamous cell carcinoma, cir-ITCH binding to miR-7, miR-17, and miR214 was reduced compared with that in adjacent non-cancerous tissues. This could facilitate linear ITCH production and thereby inactivate the Wnt/ $\beta$-catenin signaling pathway via the ubiquitinated degradation of phosphorylated Dvl2 [34]. There are sixteen putative target sites for miR-138 in circular Sry RNA, clearly indicating that Sry circRNA could act as a miR138 sponge [24]. These findings indicate that a predisposing factor for cancers may involve the disruption of the equilibrium of the interlaced ceRNA network [64].

We predicted the reciprocal patterns of differentially expressed circRNAs with complementary miRNAs and constructed a network of the most aberrantly expressed circRNAs and their interacting miRNAs, providing tremendous value for studies of circRNAs as ceRNAs. Given that miRNAs are associated with the progression of resistant cancers, circRNAs could be involved in managing the sensitivity of NSCLC to chemical drugs by targeting miRNAs. The overwhelming majority of circRNAs in the circRNA/miRNA interaction network were related to more than one miRNA. Many previously documented miRNAs governing the sensitivity of lung cancer to chemotherapy could interact dynamically with dysregulated circRNAs in our examination. Remarkably, among these miRNAs, only two (miR-141 and miR-34c-5p) were predicted to pair with the MREs of two out of the top 20 differentially expressed circRNAs. miR-141 mimics in ovarian cancer cells increase sensitivity to paclitaxel, and the knockdown of miR-141 results in the down-regulation of E-cadherin and the up-regulation of Vimentin and Fibronectin, triggering mesenchymal transition and the up-regulation of the $\beta$-tubulin isotype TUBB3, rendering cells resistant to paclitaxel and carboplatin [31]. MiR-34c-5p confers resistance to taxol-mediated apoptosis via p53 downregulation, silencing its target genes Bcl-2-modifying factor (Bmf) and c-myc, in lung cancer [32]. Additionally, miR-337-3p modulates the cellular response to paclitaxel and enhances paclitaxel-induced G2/M arrest in NSCLC cells by mediating the decrease in its direct regulatory targets STAT3 and RAP1A [68]. MiR-181a modulates paclitaxel sensitivity by directly binding to lncRNA-CCAT1 mRNA, which acts as the sponge of miR-181a, and by regulating cell apoptosis by targeting CPEB2 [69]. miR-181a also could be up-regulated by another IncRNA; SNHG12 silencing leads to the inhibition of the MAPK/slug pathway by decreasing phosphorylated MAPK1 (p-MAPK1), phosphorylated MAP2K1 (p-MAP2K1), and Slug levels [70]. Upregulated miR-181a was associated with paclitaxel resistance in A549 cells with the EMT phenotype. MiR-181a regulates the EMT process by hindering the protein expression of PTEN and increases the cell response to paclitaxel. Hence, we hypothesized that circRNAs promote the resistance of NSCLC cells to taxol via contact with miRNAs.

Finally, we explored the biological functions and detailed mechanisms by which differential circRNA expression is involved in resistance to taxol using a GO analysis 
and pathway annotation to determine the regulatory roles of host genes. We identified numerous GO terms and pathways implicated in resistance to drugs for cancer treatment. Taken together, these findings suggested that dysregulated circRNAs prevent the sensitivity of NSCLC to taxol. Nevertheless, further large-scale studies are required to illuminate the functional mechanisms of resistance-related circRNAs.

\section{Conclusion}

Our results revealed the dysregulation of circRNAs in taxol-resistant A549 cells compared with parental A549 cells. We constructed a circRNA/miRNA interaction network and implemented GO and pathway analyses of host genes of differentially expressed circRNAs, supporting the inference that circRNAs function as assistants in the occurrence and progression of the resistance of NSCLC to taxol. As a result, the emerging circRNAs expand our knowledge of the mechanisms underlying NSCLC resistance and are promising biological markers and therapeutic targets. These results throw out a minnow to catch a whale and provide a basis for further studies of the roles of circRNAs in taxol-resistant NSCLC.

\section{Acknowledgements}

This work was supported by the National Natural Science Foundation of China (Nos. 81402176, 81402093, and 81472296), Natural Science Foundation of Jiangsu Province, China (No. BK20140288), Science Technology Project of Suzhou Xiangcheng District (Nos. XJ201456 and XJ201532) and the Industry-University Research Cooperation prospective joint research project of Jiangsu Province (No. BY2015039-01).

\section{Disclosure Statement}

The authors declare to have no conflict of interests.

\section{References}

-1 Xu G, Chen J, Pan Q, Huang K, Pan J, Zhang W, Chen J, Yu F, Zhou T, Wang Y: Long noncoding RNA expression profiles of lung adenocarcinoma ascertained by microarray analysis. Plos One 2014; 9:e104044.

-2 Torre LA, Bray F, Siegel RL, Ferlay J, Tieulent JL, Jemal A: Global cancer statistics, 2012. CA-Cancer J Clin 2015;65:87-108.

3 Molina JR, Yang P, Cassivi SD, Schild SE, Adjei AA: Non-small cell lung cancer:epidemiology, risk factors, treatment, and survivorship. Mayo Clin Proc 2008;83:584-594.

4 Faivre C, El Cheikh R, Barbolosi D, Barlesi F: Mathematical optimisation of the cisplatin plus etoposide combination for managing extensive-stage small-cell lung cancer patients. Brit J Cancer 2017;116:344-348.

5 Sacco PC, Gridelli C: An update on the developing mitotic inhibitors for the treatment of non-small cell carcinoma. Expert Opin Emerg Dr 2017;22:213-222.

6 Chang A: Chemotherapy, chemoresistance and the changing treatment landscape for NSCLC. Lung Cancer 2011;71:3-10.

7 Azzoli CG, Baker SJ, Temin S, Pao W, Aliff T, Brahmer J, Johnson DH, Laskin JL, Masters G, Milton D, Nordquist L, Pfister DG, Piantadosi S, Schiller JH, Smith R, Smith TJ, Strawn JR, Trent D, Giaccone G, American Society of Clinical 0: American Society of Clinical Oncology Clinical Practice Guideline update on chemotherapy for stage IV non-small-cell lung cancer. J Clin Oncol 2009;27:6251-6266. 


\section{Cellular Physiology Cell Physiol Biochem 2018;48:2046-2060 \begin{tabular}{l|l} 
and Biochemistry Published online: August 9, 2018 & $\begin{array}{l}\text { D } 2018 \text { The Author(s). Published by S. Karger AG, Basel } \\
\text { www.karger.com/cpb }\end{array}$ \\
\hline
\end{tabular}}

8 D'Addario G, Fruh M, Reck M, Baumann P, Klepetko W, Felip E, Group EGW: Metastatic non-small-cell lung cancer: ESMO Clinical Practice Guidelines for diagnosis, treatment and follow-up. Ann Oncol 2010;21:v116119.

\$ Tay Y, Rinn J, Pandolfi PP: The multilayered complexity of ceRNA crosstalk and competition. Nature 2014;505:344-352.

10 Jonas S, Izaurralde E: Towards a molecular understanding of microRNA-mediated gene silencing. Nat Rev Genet 2015;16:421-433.

11 Quinn JJ, Chang HY: Unique features of long non-coding RNA biogenesis and function. Nat Rev Genet 2016;17:47-62.

-12 Schmitt AM, Chang HY: Long Noncoding RNAs in Cancer Pathways. Cancer Cell 2016;29:452-463.

13 Lyu D, Huang S: The emerging role and clinical implication of human exonic circular RNA. RNA Biol 2016;2:1-7.

14 Salzman J, Gawad C, Wang PL, Lacayo N, Brown PO: Circular RNAs are the predominant transcript isoform from hundreds of human genes in diverse cell types. Plos One 2012;7:e30733.

15 Qu S, Zhong Y, Shang R, Zhang X, Song W, Kjems J, Li H: The emerging landscape of circular RNA in life processes. RNA Biol 2017:14:992-999.

16 Panda AC, Grammatikakis I, Munk R, Gorospe M, Abdelmohsen K: Emerging roles and context of circular RNAs. WIRES RNA 2016;8: DOI:10.1002/wrna.1386.

17 Meng S, Zhou H, Feng Z, Xu Z, Tang Y, Li P, Wu M: CircRNA: functions and properties of a novel potential biomarker for cancer. Mol Cancer 2017;16:94.

18 Barrett SP, Salzman J: Circular RNAs: analysis, expression and potential functions. Development 2016;143:1838-1847.

19 Suzuki H, Tsukahara T: A view of pre-mRNA splicing from RNase R resistant RNAs. Int J Mol Sci 2014;15:9331-9342.

-20 Jeck WR, Sorrentino JA, Wang K, Slevin MK, Burd CE, Liu J, Marzluff WF, Sharpless NE: Circular RNAs are abundant, conserved, and associated with ALU repeats. RNA 2013;19:141-157.

-21 Salzman J, Chen RE, Olsen MN, Wang PL, Brown PO: Cell-type specific features of circular RNA expression. PLos Genet 2013;9:e1003777.

22 Rybak-Wolf A, Stottmeister C, Glazar P, Jens M, Pino N, Giusti S, Hanan M, Behm M, Bartok O, Ashwal-Fluss R, Herzog M, Schreyer L, Papavasileiou P, Ivanov A, Ohman M, Refojo D, Kadener S, Rajewsky N: Circular RNAs in the Mammalian Brain Are Highly Abundant, Conserved, and Dynamically Expressed. Mol Cell 2015;58:870-885.

23 Szabo L, Morey R, Palpant NJ, Wang PL, Afari N, Jiang C, Parast MM, Murry CE, Laurent LC, Salzman J: Statistically based splicing detection reveals neural enrichment and tissue-specific induction of circular RNA during human fetal development. Genome Biol 2015;16:126.

-24 Hansen TB, Jensen TI, Clausen BH, Bramsen JB, Finsen B, Damgaard CK, Kjems J: Natural RNA circles function as efficient microRNA sponges. Nature 2013;495:384-388.

25 Xin Z, Ma Q Ren S, Wang G, Li F: The understanding of circular RNAs as special triggers in carcinogenesis. Brief Funct Genomics 2017;16:80-86.

-26 Qu S, Yang X, Li X, Wang J, Gao Y, Shang R, Sun W, Dou K, Li H: Circular RNA: A new star of noncoding RNAs. Cancer Lett 2015;365:141-148.

27 Zhao ZJ, Shen J: Circular RNA participates in the carcinogenesis and the malignant behavior of cancer. RNA Biol 2015:1-8.

28 Mallini P, Lennard T, Kirby J, Meeson A: Epithelial-to-mesenchymal transition: what is the impact on breast cancer stem cells and drug resistance. Cancer Treat Rev 2014;40:341-348.

29 Chen D, Huang J, Zhang K, Pan B, Chen J, De W, Wang R, Chen L: MicroRNA-451 induces epithelialmesenchymal transition in docetaxel-resistant lung adenocarcinoma cells by targeting proto-oncogene c-Myc. Eur J Cancer 2014;50:3050-3067.

-30 Jin Z, Guan L, Song Y, Xiang GM, Chen SX, Gao B: MicroRNA-138 regulates chemoresistance in human nonsmall cell lung cancer via epithelial mesenchymal transition. Eur Rev Med Pharmaco 2016;20:1080-1086.

31 Brozovic A, Duran G, Wang Y, Francisco E, Sikic B: The miR-200 family differentially regulates sensitivity to paclitaxel and carboplatin in human ovarian carcinoma OVCAR-3 and MES-OV cells. Mol Oncol 2015;9:1678-1693. 


\section{Cellular Physiology Cell Physiol Biochem 2018;48:2046-2060 \begin{tabular}{ll|l} 
DOI: 10.1159/000492543 & and Biochemistry & $\begin{array}{l}\text { 2018 The Author(s). Published by S. Karger AG, Basel } \\
\text { www.karger.com/cpb }\end{array}$ \\
\hline Xublished online: August 9, 2018
\end{tabular}}

32 Catuogno S, Cerchia L, Romano G, Pognonec P, Condorelli G, de Franciscis V: miR-34c may protect lung cancer cells from paclitaxel-induced apoptosis. Oncogene 2013;32:341-351.

-33 Memczak S, Jens M, Elefsinioti A, Torti F, Krueger J, Rybak A, Maier L, Mackowiak SD, Gregersen LH, Munschauer M, Loewer A, Ziebold U, Landthaler M, Kocks C, le Noble F, Rajewsky N: Circular RNAs are a large class of animal RNAs with regulatory potency. Nature 2013;495:333-338.

-34 Li F, Zhang L, Li W, Deng J, Zheng J, An M, Lu J, Zhou Y: Circular RNA ITCH has inhibitory effect on ESCC by suppressing the Wnt_ $\beta$-catenin pathway. Oncotarget 2015;6:6001-6013.

-35 Andreoli M, Persico M, Kumar A, Orteca N, Kumar V, Pepe A, Mahalingam S, Alegria AE, Petrella L, Sevciunaite L, Camperchioli A, Mariani M, Di Dato A, Novellino E, Scambia G, Malhotra SV, Ferlini C, Fattorusso C: Identification of the first inhibitor of the GBP1:PIM1 interaction. Implications for the development of a new class of anticancer agents against paclitaxel resistant cancer cells. J Med Chem 2014;57:7916-7932.

-36 McGrail DJ, Khambhati NN, Qi MX, Patel KS, Ravikumar N, Brandenburg CP, Dawson MR: Alterations in ovarian cancer cell adhesion drive taxol resistance by increasing microtubule dynamics in a FAK-dependent manner. Sci Rep 2015;5:9529.

37 Wu G, Qin X, Guo J, Li T, Chen J: AKT/ERK activation is associated with gastric cancer cell resistance to paclitaxel. Int J Clin Exp Patho 2014;7:1449-1458.

-38 Hodkinson PS, Mackinnon AC, Sethi T: Extracellular matrix regulation of drug resistance in small-cell lung cancer. Int J Radiat Biol 2009;83:733-741.

39 Sang XB, Sun KX, Wang LL, Chen S, Wu DD, Zong ZH, Zhao Y: Effects and mechanism of RhoC downregulation in suppressing ovarian cancer stem cell proliferation, drug resistance, invasion and metastasis. Oncol Rep 2016;36:3267-3274.

40 Wei L, Yin F, Zhang W, Li L: STROBE-compliant integrin through focal adhesion involve in cancer stem cell and multidrug resistance of ovarian cancer. Medicine 2017;96:e6345.

-41 Villegas-Pineda JC, Toledo-Leyva A, Osorio-Trujillo JC, Hernandez-Ramirez VI, Talamas-Rohana P: The translational blocking of alpha5 and alpha6 integrin subunits affects migration and invasion, and increases sensitivity to carboplatin of SKOV-3 ovarian cancer cell line. Exp Cell Res 2017;351:127-134.

-42 Chen X, Zhang X, Shen Y, Fan L, Ren M, Wu Y: Synthetic paclitaxel-octreotide conjugate reversing the resistance of A2780_Taxol to paclitaxel in xenografted tumor in nude mice. Oncotarget 2016;7:8345183461.

43 Park S, Seong M, Lee H: p38 MAPK-induced MDM2 degradation confers paclitaxel resistance through p53mediated regulation of EGFR in human lung cancer cells. Oncotarget 2016;7:8184-8199.

44 Yang Y, Li H, Hou S, Hu B, Liu J, Wang J: The noncoding RNA expression profile and the effect of lncRNA AK126698 on cisplatin resistance in non-small-cell lung cancer cell. Plos One 2013;8:e65309.

45 Liu Z, Sun M, Lu K, Liu J, Zhang M, Wu W, De W, Wang Z, Wang R: The long noncoding RNA HOTAIR contributes to cisplatin resistance of human lung adenocarcinoma cells via downregualtion of p21(WAF1/ CIP1) expression. Plos One 2013;8:e77293.

46 Pan B, Chen Y, Song H, Xu Y, Wang R, Chen L: Mir-24-3p downregulation contributes to VP16-DDP resistance in small-cell lung cancer by targeting ATG4A. Oncotarget 2015;6:317-331.

-47 Bahn JH, Zhang Q Li F, Chan TM, Lin X, Kim Y, Wong DT, Xiao X: The landscape of microRNA, Piwiinteracting RNA, and circular RNA in human saliva. Clin Chem 2015;61:221-230.

48 Memczak S, Papavasileiou P, Peters 0, Rajewsky N: Identification and Characterization of Circular RNAs as a New Class of Putative Biomarkers in Human Blood. Plos One 2015;10:e0141214.

49 Zhao Y, Alexandrov PN, Jaber V, Lukiw WJ: Deficiency in the Ubiquitin Conjugating Enzyme UBE2A in Alzheimer's Disease (AD) is Linked to Deficits in a Natural Circular miRNA-7 Sponge (circRNA; ciRS-7). Genes 2016;7: pii: E116.

50 Xie H, Ren X, Xin S, Lan X, Lu G, Lin Y, Yang S, Zeng Z, Liao W, Ding Y, Liang L: Emerging roles of circRNA_001569 targeting miR-145 in the proliferation and invasion of colorectal cancer. Oncotarget 2016;7:26680-26691.

51 Guo JN, Li J, Zhu CL, Feng WT, Shao JX, Wan L, Huang MD, He JD: Comprehensive profile of differentially expressed circular RNAs reveals that hsa_circ_0000069 is upregulated and promotes cell proliferation, migration, and invasion in colorectal cancer. Oncotargets Ther 2016;9:7451-7458. 


\section{Cellular Physiology Cell Physiol Biochem 2018;48:2046-2060 \begin{tabular}{l|l} 
DOI: 10.1159/000492543 & and Biochemistry \\
Published online: Aungust 9, 2018 & $\begin{array}{l}\text { O 2018 The Author(s). Published by S. Karger AG, Basel } \\
\text { mww.karger.com/cpb }\end{array}$
\end{tabular} \\ Xu et al.: Circrnas in Taxol-Resistant NSCLC}

52 Wang X, Zhang Y, Huang L, Zhang J, Pan F, Li B, Yan Y, Jia B, Liu H, Li S, Zheng W: Decreased expression of hsa_circ_001988 in colorectal cancer and its clinical significances. Int J Clin Exp Patho 2015;8:1602016025.

53 Chen J, Li Y, Zheng Q, Bao C, He J, Chen B, Lyu D, Zheng B, Xu Y, Long Z, Zhou Y, Zhu H, Wang Y, He X, Shi Y, Huang S: Circular RNA profile identifies circPVT1 as a proliferative factor and prognostic marker in gastric cancer. Cancer Lett 2016;388:208-219.

54 Li P, Chen S, Chen H, Mo X, Li T, Shao Y, Xiao B, Guo J: Using circular RNA as a novel type of biomarker in the screening of gastric cancer. Clin Chim Acta 2015;444:132-136.

-55 Xia W, Qiu M, Chen R, Wang S, Leng X, Wang J, Xu Y, Hu J, Dong G, Xu PL, Yin R: Circular RNA has_ circ_0067934 is upregulated in esophageal squamous cell carcinoma and promoted proliferation. Sci Rep 2016;6:35576.

56 Sand M, Bechara FG, Gambichler T, Sand D, Bromba M, Hahn SA, Stockfleth E, Hessam S: Circular RNA expression in cutaneous squamous cell carcinoma. J Dermatol Sci 2016;83:210-218.

57 Qin M, Liu G, Huo X, Tao X, Sun X, Ge Z, Yang J, Fan J, Liu L, Qin W: Hsa_circ_0001649: A circular RNA and potential novel biomarker for hepatocellular carcinoma. Cancer Biomark 2016;16:161-169.

58 Umeyama H, Iwadate M, Taguchi Y: TINAGL1 and B3GALNT1 are potential therapy target genes to suppress metastasis in non-small cell lung cancer. BMC Genomics 2014;15:S2.

59 Wu J, He Z, Wang D, Sun F: Depletion of JMJD5 sensitizes tumor cells to microtubule-destabilizing agents by altering microtubule stability. Cell Cycle 2016;15:2980-2991.

60 Ai J, Li W, Zeng R, Xie Z, Liu H, Hou M, Tan G: Blockage of SSRP1/Ets-1/Pim-3 signalling enhances chemosensitivity of nasopharyngeal carcinoma to docetaxel in vitro. Biomed Pharmacother 2016;83:10221031.

-61 Marshall JC, Collins JW, Nakayama J, Horak CE, Liewehr DJ, Steinberg SM, Albaugh M, Vidal-Vanaclocha F, Palmieri D, Barbier M, Murone M, Steeg PS: Effect of inhibition of the lysophosphatidic acid receptor 1 on metastasis and metastatic dormancy in breast cancer. J Natl Cancer I 2012;104:1306-1319.

62 Yuan B, Wu C, Wang X, Wang D, Liu H, Guo L, Li XA, Han J, Feng H: High scavenger receptor class B type I expression is related to tumor aggressiveness and poor prognosis in breast cancer. Tumor Biol 2016;37:3581-3588.

63 Uramoto H, Akyürek L, Hanagiri T: A positive relationship between filamin and VEGF in patients with lung cancer. Anticancer Res 2010;30:3939-3944.

64 Salmena L, Poliseno L, Tay Y, Kats L, Pandolfi P: A ceRNA hypothesis: the Rosetta Stone of a hidden RNA language? Cell 2011;146:353-358.

65 Xu H, Guo S, Li W, Yu P: The circular RNA Cdr1as, via miR-7 and its targets, regulates insulin transcription and secretion in islet cells. Sci Rep 2015;5:12453.

66 Geng HH, Li R, Su YM, Xiao J, Pan M, Cai XX, Ji XP: The Circular RNA Cdr1as Promotes Myocardial Infarction by Mediating the Regulation of miR-7a on Its Target Genes Expression. Plos One 2016;11:e0151753.

67 Li J, Yang J, Zhou P, Le Y, Zhou C, Wang S, Xu D, Lin H, Gong Z: Circular RNAs in cancer_novel insights into origins, properties, functions and implications. Am J Cancer Res 2015;5:472-480.

-68 Du L, Subauste MC, DeSevo C, Zhao Z, Baker M, Borkowski R, Schageman JJ, Greer R, Yang CR, Suraokar M, Wistuba, II, Gazdar AF, Minna JD, Pertsemlidis A: miR-337-3p and its targets STAT3 and RAP1A modulate taxane sensitivity in non-small cell lung cancers. Plos One 2012;7:e39167.

69 Wang Q, Zhang W, Hao S: LncRNA CCAT1 modulates the sensitivity of paclitaxel in nasopharynx cancers cells via miR-181a/CPEB2 axis. Cell Cycle 2017;16:795-801.

70 Wang P, Chen D, Ma H, Li Y: LncRNA SNHG12 contributes to multidrug resistance through activating the MAPK/Slug pathway by sponging miR-181a in non-small cell lung cancer. Oncotarget 2017;8:8408684101. 